\title{
Arnaldo Canziani* \\ On the Accounting Regulation for the European Private Sector
}

https://doi.org/10.1515/ael-2017-0015

Published online June 27, 2017

Abstract: This article is based upon a speech given at the international workshop on "Which accounting regulation for Europe's economy and society?" held at the European Parliament, Strasbourg, on May 20, 2015, in tribute to Mr Jérôme Haas (1963-2014), first chairman of the Accounting Standards Authority of France (ANC).

Keywords: European accounting regulation, true and fair view, IFRS

\section{Table of contents}

1 Introduction

2 English v. Continental Europe Accounting: the Technical Differences

2.1 True and fair

2.2 Cautiousness versus current values

2.3 Two juxtaposed accounting systems, and their basic differences

3 The Technical Nature of IAS, later IFRS

4 From Technicalities to Politics: Devolution of Sovereignty?

5 Conclusions: Harmonisation or Hodgepodge?

References

Accounting for the European Private Sector: Reconsidering Accounting Objectives for Economy and Finance

1. “Accounting for Europe's Economy and Society: Considerations for Financial Stability, Economic Development and the Public Good" by Yuri Biondi, https://doi.org/10.1515/ael2017-0018

2. "On the Accounting Regulation for the European Private Sector" by Arnaldo Canziani, https://doi.org/10.1515/ael-2017-0015

3. "The Need to Reform the Dangerous IFRS System of Accounting" by Jacques Richard, https://doi.org/10.1515/ael-2017-0017

4. “International Financial Reporting Standards (IFRS): Stress Testing in Financialized Reporting Entities" by Colin Haslam, https://doi.org/10.1515/ael-2017-0016

5. “Open Debate on Accounting for the European Private Sector” by Imke Graeff, https://doi. org/10.1515/ael-2017-0024

*Corresponding author: Arnaldo Canziani, Brescia University, 25121 Brescia BS, Italy, E-mail: canziani@unibs.it 


\section{Introduction}

Not to rephrase Casablanca as well as other classic movies, also in the field of accounting one could easily recognise - under the sweet, common veil of harmonisation, common principles, and other (pseudo)-technicalities - the same old story, the fight for money and glory. One could easily recognise - to say this better - the competition among nations to impose their own systems to others, as in every field peace - it was told by Karl v. Clausewitz- is the simple continuation of war by only different means. In the special case we are speaking about, the war among accounting cultures (Gray, 1988) to establish one only accounting dominance.

This given, in the special field of European accounting regulation one could easily differentiate - since late 70s, or early 80s - three stages of growing an importance and, more important, of gradual supremacy of Anglo-Saxon rules in the field. These steps are representable as such: (i) by EU Directives, with the introduction of the true and fair prescription stemming from the UK Companies Act, 1948; (ii) by their later referring to common accounting principles, which were anyway neither common nor principles, but mere uses codified as common ones in the Anglo-Saxon world; (iii) by their integration or completion (national implementations included) by professional codified uses of various an imprint, i. e. IFRS (and others?).

Now, not to seclude the problem into personal recollections, nor to treat it by anecdotes, the formative process of EU Directives 4th and 7th effectively represented a 'critical event' on the road to the Anglicisation of the accounting world of today. In addition, it resulted to be a Trojan horse for the transition - in Europe too - from civil law to common law in the field of accounting (and others). As a matter of fact, due merely to age (and luck), this writer was permitted to be member of various EU study groups preparing - and later amending - the above mentioned directives: as a consequence, he perfectly remembers the various stages of their cooking, and serving as well, at both European and national level. This way he takes the liberty here to squeeze in just a few lines (not to be as colourful as he could) the dynamics of those works, a jointly technical and political process of long run, anyway with clear-cut goals since the beginning.

Originally, the framework of the 4th and the 7th Directives was largely (totally?) of French-German an imprint, this meaning (i) order, (ii) precision (maybe too much so?), (iii) clarté (according to the principle ce qui n'est pas clair n'est pas français). The same for the working language within committees: French. But along years, especially once Great Britain entered the EU and succeeded to influence processes and decisions, the new Chairman (in many 
cases a Holland or Danish executive of the so-called Big 8, as Great Britain politically speaking - preferred to stay officially apart, influencing the dynamics behind the scenes) started saying pou-ròn nou: pa:lé ló fan-sè. Nobody was so formal nor so bold to oppose, and as a result the works were conducted - and moreover the drafts were prepared - in the English language, a practical and a 'transmissive language' the technical intricacies of which were not so simply manageable by non-native delegates.

This way works ran fast, with no chance for participants (or very scarce ones) both to convert national institutes and provisions into English ones and into English language as well, as it was not so easy for non-native to suggest modifications having sense from the point of view of both English language, and culture (delegates non fluent in English apart).

These changes brought about a set of consequences, the systemic result of which not only become technically and politically relevant but resulted - as a matter of fact - in the large overturning of previous projects, principles, culture as well as, in just one word, of the whole previous continental Weltanschauung.

As a result, the final version of the 4th and 7th EU Directives resulted to be largely English-minded, in addition shaped - in various cases - on the Companies Act of 1948 (Canziani, 1988; Gray \& Coenenberg, 1988).

As the juridical complexities coming from this process (or these processes in general) have been narrated elsewhere, we limit ourselves here to just a few critical remarks respectively concerning (i) true and fair, (ii) caution (prudence) v. current values, (iii) juxtaposed accounting systems.

\section{English v. Continental Europe Accounting: the Technical Differences}

\subsection{True and fair}

The prescription 'true and fair' is a well-known landmark of the Companies Act of 1948; anyway, it seems of the utmost interest to recall here the origins of that provision.

While, during preparatory works, alternative proposals - or even wording - were discussed (among them full and fair, full and true, and others), all of a sudden true and fair gained the upper hand. Unfortunately, true and fair was as uncommon in accounting as rare within English language, were it had been lost after John Donne's Song - Go and Catch a Falling Star (1600), where he said: 


\section{I swear, nowhere,}

lives a woman

true and fair.

Male chauvinism or not (in this case it being totally attributable to that Author some four-hundred years ago), the ironic, sceptical content of that suggestion is now crying.

In subsequent years, English accounting theory was not at a level of defining once for all the meaning and content of true and fair (t\&f), which lived for decades as a debated topic till the blueprint of Flint, $A$ true and fair view in company accounts. This work too, anyway, albeit often quoted did not seem to be a resolving solution to the problem, as within coulisses Englishmen first were used to comment "Two only persons in Great Britain know what true and fair is: professor Flint ... and God!". The result was on one side the substantial absence of jurisdiction on t\&f, on the other the paving the way to the so-called < diffused jurisdiction >, this obeying from case to case to different situations, values, and opinions as well (Biondi, 2011; Richard, 2005).

More seriously, multiple problems anyway arose from the technical point of view, as it was now compulsory for every Member Country to translate true and fair by neither substantial nor merely semantic ways. Intricacies apart, this was something more than a translation: it consisted (even if seldom perceived) in the transplanting from common law - i.e. from the opinion of the single judge as the relevance of precedents is regarded- to civil law.

This meant to pass to obey to Codes, and something more. 'Implementation' meant in fact $t \& f$ to be framed within systems hierarchically obeying (i) to general principles of law (bona fides included), (ii) to Codes, (iii) to laws and procedures. This meant - in addition - to precise the prescriptive contents, as continental countries were not at all interested in 'a' true and fair view but, in case, in 'the' true and fair view.

One major problem consisted in $t \& f$ being neither a general provision nor a 'general clause' according to civil law, these being on the contrary general decision models to be connected to laws to solve cases in point (e.g. bona fides i. e. good faith, reasons beyond one's control, and so on).

As a consequence, as in civil law countries the only way to be fair is to be true, and the only way to be true is to conform to law, every country - even if under different denominations (image fidèle in France, bilancio veritiero $e$ corretto in Italy) -:

1. Made reference to the general principles of exactness, clarity, and caution;

2. Adapted these principles to the different nature of accounting values, this way prescribing: 
a. Objective truth (measurements) for entry-values (current costs; sales; end-period debts and cash);

b. Evaluations for stocks and credits, due to their prospective benchmark ;

c. Estimates for depreciation values, whose verification has to be referred to their whole economic life nor to punctual end-year benchmarks.

In Germany, in particular, as (i) the 4th Directive spoke of $t \& f$ without defining its premise rule of law (die Grundnormen), (ii) the special law prevails over the general one, (iii) $t \& f$ did not concern accounting measurements nor evaluations but merely formats and notes.

The whole situation was of little a satisfaction from the general point of view: harmonisation seemed to represent, substantially, little more than a label, especially as regarded the Anglo-Saxon world v. Continental Europe. Moreover, it was largely unsatisfactory for the powerful interests represented by Big 8 (later on Big 5, or less) as well as by the international finance of Anglo-Saxon an imprint.

So, the characters of these latter vested interests started to back, publicise and suggest to draw upon International Accounting Standards (IAS) to equalise at international level both preparation and control of annual accounts. This would help, ex ante at least, a factual harmonisation over the so many national accounting residuals; moreover, it would have stressed the monopolistic domain of Big 8 over European accounting, and consultancy as well.

\subsection{Cautiousness versus current values}

One more substantial difference between Anglo-Saxons versus Continental Europe accounting was the general dominance here of the cautiousness principle versus the preference for current values there.

It is not enough: In Great Britain, cautiousness is now so far from common understanding in the field of annual accounts that its traditional name, prudence (as prudence in France, prudenza in Italy, prudencia in Spanish), is now in Great Britain mainly a character in comedies, as well as in the US the smallest isle of Rhode Island Sound. Prudence on the contrary (of which cautiousness to be true in only a part), cooperated to form the traditional view of the world since antiquity (from Aristotle's phronesis -<practical wisdom and distinctive criterion >, Etica Nicomachea, 1142a - to Cicero to Saint Thomas the Aquinas and so on), this way being judged a relevant topic in every field of action, from families to politics.

As far as annual accounts are concerned, in particular, its general suggestions stated as follows:

1. Assets shall be evaluated at the minimum exit value;

2. Liabilities shall be valued at the maximum reimbursement value; 
3. Costs will be included even if probable ones;

4. Revenues will be inscribed only if ascertained;

5. No increase in asset-values can be inscribed, but obeying to ad hoc laws;

6. The whole evaluating process must take into account all information obtained between the closing of the financial year and the preparation of annual accounts.

This way, prudence was not only intended as a fundamental accounting principle regarding the income recognition - gains were not to be anticipated until very probable -: it was something more important, involving the whole representation of the firm economy.

At its basis there was a totally different conception of the firm as such, and of annual accounts consequently. The first one can be represented - synthetically, and paradoxically as well - by the famous phrase of Walter Rathenau, the German statesman saying: "Companies have three kind of enemies: workers, creditors ... and shareholders!” as the former ones ask for salaries, the second ones for interests and reimbursements, the latter ones for dividends. Apart from provocation, this represented in short the concept of Unternehmen an sich (the company as such), with its own right to live, and to continue to live in space-time under competition, this way protecting at best the interests of stakeholders as a whole.

The Anglo-Saxon view - also influenced by the different structure of capital markets as well as the distribution of wealth and savings - was just opposite, it paying overwhelming an attention to investors, and the transparency of information presented them year by year (and intra-year in case).

The former vision of the world could have obviously implied over-prudence, lack of information, restraints in dividends, hidden or implicit reserves and so on - but at the same time, when honestly conducted, it tended to reinforce firms, exactly avoiding unscrupulous and easy-going behaviours (in Switzerland e. g., the Companies Code traditionally stated < hidden reserves are permitted $>$, and maybe not by a chance Switzerland never presented such cases as Enron, Lehman Brothers and others in continental Europe after the UE Directives from Crédit Lyonnais to Parmalat, companies whose transparent, fully disclosed information ended in annual accounts duly audited and signed).

The latter interpretation of annual accounts, the Anglo-Saxon one, obviously rejected that imprint, supporting on the contrary current values, revaluations, replacement value as a benchmark for depreciation, and so on. That is why, and maybe not by chance, during the forming process of both the 4th and the 7th EU Directives prudence was branded as conservatism, thus paving the way to Anglo-Saxon contemporary uses, especially the ones inspiring the IAS and shaping their rules. 
As a further result of this (mis) conception, IASB abandoned the principle of prudence, while in parallel the British Reporting Standard FRS 18 relegated prudence - along with consistency - among desirable nor fundamental qualities of annual accounts.

In addition to the economic and political reasons, also technical reasons were therefore in action to purport the relevance of IAS and suggest their adoption.

\subsection{Two juxtaposed accounting systems, and their basic differences}

Anyhow, some basic differences in the accounting systems of Great Britain versus Continental Europe lied at the very base of all the above mentioned differences, and different interpretations as well.

The former one, in fact, was still relying on the conception of the firm as a set of assets, while the latter ones - after Irving Fisher, Eugen Schmalenbach, and Gino Zappa in particular - progressed to the concept of the firm as a going concern (Busse von Colbe, 1996; Canziani, 2013).

Badly squeezing the problem, the first conception flourishes as an assetbased one, directly linked to cost-accounting (especially in the form of full costing), adopting FIFO versus LIFO as it supposes accountability to follow directly (and mechanically) the flow of operations from raw materials to finished goods, and so on.

The latter ones, on the contrary, decided since the 1920 s to pay attention to income as (i) every wealth was originally income, (ii) the value of wealth (i. e. assets) is a function of its future income-streams.

Consequently, attention was paid more to profit and loss (P\&L) than to assets and liabilities (A\&L): the former expressed the juxtaposition between costs and revenues representing the very activity of the firm, the latter one reflected the values of the former (e.g. depreciation allowances, stocks, other) under the principle of prudence. As a consequence - to offer here just two cases -, annual accounting was (partially) separated from cost accounting, this being in particular based on LIFO versus FIFO.

\section{The Technical Nature of IAS, later IFRS}

Any discussion about IAS, now IFRS, is out of place here. Anyhow, as we repeatedly made reference to them, just a few words can be added to propose 
some reflections as the accounting regulation for the European private sector is concerned.

As we all know, the coming in power of IAS/IFRS - historical factors apart, among them (i) the British Empire now Commonwealth, (ii) the US world influence after Bretton Woods, the Marshall Plan, the Cold War and more recently Middle East wars - is largely due to the international expansion of Anglo-Saxon MNCs (Multinational Companies) and the more recent globalisation of financial flows. It is due, in addition, to the clever action of British politics (and lobbying as well) at EU and European Parliament level. That governance being driven by Anglo-Saxons centres like London and New York, as well as by Anglo-Saxon actors (multinational companies, pension funds, investments funds of every type, hedge funds included), it is plain understandable the preference of them all - or their need so to say - for such accounting bases able to grant (i) familiarity of technical concepts, (ii) immediate understandability of data, (iii) reliability of the same, especially as far as guarantees are concerned.

This way IAS gained space along years stemming from the 1970s (IASC was promoted by IFAC in 1973), then spreading from the Anglo-Saxon world to Continental Europe, especially after their formal introduction by the EU Regulations of July 19th, 2002, n. 1606, and September 29th, 2003, n. 1725 and further ones as well, of homologating a nature. At the end - which means today - IAS are applied in some 120 countries, which allows the same vulgata to say that "IFRS is a set of accounting standards developed by an independent not-for-profit organisation called International Accounting Standards Board; IFRS provide a global framework to prepare and disclose financial statements of public companies”.

No doubt can be raised against the maybe most important advantage of IAS, their extremely analytical accounting treatment of any business operation.

But from the systemic point of view, one cannot forget - due to their adoption - the displacement of Codes and Statutes in favour of uses, privately coordinated, movable along time, and as international as they were diffused by powerful international interests, vested ones in some cases.

In addition, the extension of IAS/IFRS outside the Anglo-Saxon world meant as a matter of fact - and does mean, both today and in the future - the substitution (i) of collective standards to norms, (ii) of a private jurisdiction to State laws, (iii) of common-law uses to civil law Codes and statutes. This means, in most cases, the substitution of English accounting - with its sophisticated but old-fashioned bases - to modern accounting, of the income-type in particular. Some today highly debated problems stemming from their adoption - mark to market, 'fair' values in general - derive in fact from the clash between some classical 'world principles' 
(neutrality, consistency, caution among them) and the financialisation approach of IAS/IFRS, tending to satisfy the financial interests of financial investors. They derive, more substantially, from the clash between the concept describing the firm as a going concern, a dynamic income-producing economic unit and the opposite Anglo-Saxon ones, from the 'black box' to 'a set of assets and liabilities' (Bensadon \& Praquin, 2016; Canziani, 2016; Rayman, 2006).

In particular, some provisions like (a) substance over form, (b) 'fair' values for intangibles; (c) special technicalities to inscribe deferred taxes, leasing, foreign exchange operations, derivatives etc. contrast with some basics of Codes, not by a chance imprinting national continental legislations since the Nineteenth century: continuity, pertinence (costs and revenues belonging to the financial year, independently from either payment or collection), caution.

To conclude on the point, nor to insist on IAS being codified uses in their own nature (with their complexity, their mutability, at the end their volatility in case, inasmuch they seem to follow both advances in accounting and contingencies in some cases), a major problem seems to lie anyway on the carpet for civil-law countries: how to define boundaries, and mutual relationships as well between a private system of rules (IFRS) and State systems of norms, especially in cases where norms stem from Codes. This, in addition, once verified the true existence of the advantages their supporters preach: independence, pure technicality, efficiency, usefulness.

\section{From Technicalities to Politics: Devolution of Sovereignty?}

The repeated criticism of the above lines makes anyway little sense from the point of view of the Anglo-Saxon guidance of the economic world (China apart). This guidance given, it is plain understandable the advantage - so to say the need - for the Anglo-Saxon world to get a (so to say) uniform accounting language of Anglo-Saxon an imprint around the entire world.

A first advantage, a true private, epistemic interest, laid in the need for a guidance among so many different practices, standard setters, formal opinions, and judge sentences. The practical reference to a 'superior' authority could this way orientate practice in firmly a way, no matter if adopting the poor concept of truth of their neopositivistic imprint, where truth stems from (i) the common opinion, (ii) the duty to conform oneself to the law of majority also in the intellectual field. 
In addition, once rapidly obtained that end, the same could give at a stroke some relevant, further advantages to the nations which were - at the same time - users, monopolistic proposers of those practices, and nevertheless the characters of the political process intended to uniform accounting under the label of 'international standards'. Among those advantages, we dare to remember (i) to impose of their own language, uses, procedures to the entire economic world, from companies to auditing firms; (ii) to become the officiants, and the monopolists as well, of the new rites, or even religion, of IFRS; (iii) to conform to those conventions the international accounting thought all over the world, completing the conquering of countries passing only now to legislate on the topic and compelling other to abandon their own secular, wellgrounded traditions. On this topic, professor Richard was at the same time technically incontestable and, unfortunately, politically uninfluent:

"There are certain doubts to emit about the neutrality of the IASB: first, this organisation was composed at $50 \%$ at its higher level of representatives of the USA and Great Britain; second, this organisation goes on with, or follows, in matter of very important questions, the US change in accounting policy: no wonder that one could speak of the IASB as the 'Trojan horse' of the US accounting legislator and of its indirect will to legitimate a 'Texan model' of governance."

From the technical point of view, the epistemic inconsistency of their bases recently raised some basic doubts on their adoption in the same Anglo-Saxon world. So, just to summarise here some among the economic, juridical and social effects deriving from their adoption, one could easily remember (i) the introduction into companies' accounts of both non-market and invented values called 'fair values', as well as their messy mixture with true ones as deriving from exchanges with third parties and measured by money; (ii) the enclosure of unrealised revenues (in case fancy ones?); (iii) unreasonable increases in the value of assets, (iv) distribution of fancy dividends in case.

From the political point of view, these remarks raise once more the sense of the European Union as such, of its goals, scope, functions, and future as well, especially - and once for all- after Brexit.

Europe in fact is growingly complicated by the two-speeds of its economy, by the unsolved role of the Euro, by its centrifugal tendencies, as it was by the role of Great Britain, a nation so frequently in opposition, unconnected with Euro and linked to the US by the Anglo-Saxon solidarity. As a result, due to the defence of well-organised Anglo-Saxon vested interests, to Great Britain (and its allies) lobbying, and other, in the field of accounting a battle was lost by Europe without fighting; pejus, one major chance for Europe was lost to reaffirm its traditional system of standard, well-grounded juridical and technical values, its 
very chance to build - together with its money, and laws - a coherent European system. Whilst on the contrary, as Jérôme Haas officially declared in 2014 "We want to create our own standards in France and Europe not to depend on international standards which lead to unreliable and foolish actions”.

From the point of view of political science, such a dynamics can be called devolution of sovereignty, which sadly happened, apparently at least, without any discussion, debate, and even less voting, while It is inherent in the nature of sovereignty not to be amenable to the suit of an individual without his consent (lastly Cohen, 2012).

\section{Conclusions: Harmonisation or Hodgepodge?}

The amount of problems emerging in the field is a so huge one to oblige to skip the list of them, this way limiting us here to only mention their three most important groups.

A first set of emerging (already emerged?) problems refers to the legal ones as just now referred, i. e. the relationship (overlapping? opposition?) between stable legal rules and codified uses: these ones maybe necessary ones but belonging to a different hierarchical level, and movable ones in addition.

A second set of problems is represented by the enormous amount of technical alternatives in the field of both annual and consolidated accounts.

A third set of problems concerns the professional ones, from one-man audit firms (or so) to big, multinational firms in the field of auditing and consulting (with or without 'Chinese walls'), applying all over the world 'international principles' i. e., in so many cases, their home technicalities and uses as opposite to traditionally local ones, these ones not so parochial anyway once based on Roman Law as a common ground.

Anyway, provided this writer was not so wrong in his own reflections, some further remarks can be added now - especially from both the economic and financial standpoint - just to conclude.

We live, since some periods, within a world of (i) quantitative easing (either to react to the crisis of 2007-2008 or to give a Keynesian, supposed stimulus to effective demand), (ii) low interest rates (due to the same reasons), (iii) low cost of crude oil. The international causal factors of this situation are well-known ones, even if differently evaluated at country level also due to differentiated national and political interests.

As a result, despite of mixed expectations as well as alternate industrial situations, some stock exchanges are effectively growing from years; a sort of 
growth only temporarily troubled (up to now) by local wars in the Middle East and widespread terrorism as a reaction. In parallel, the never-ending story of firm strategies at international level goes on uninterruptedly (alliances - mergers - take-overs - spin-offs included), ranging now in some cases among continents.

Could both trends continue without any global shock coming from either extended wars or financial crises (in derivatives especially), could the growth of China continue on relatively stable bases - and with these ones the mutual financial relationship between East Asia and the US could also be maintained -, no special problem should arise (I) in the average growth of the developed world, (ii) in its substantial guidance by the same US and the Anglo-Saxon culture generally speaking.

This given, spite of the whole set of the above mentioned cultural and political doubts as well as the huge amount of technical problems in elaborating-applying-modifying IFRS, no doubt that the same IFRS will fit better - for the years to come - with both the cultural and technical premises of the present world and its financial characters.

Acknowledgements: This article was prepared for and read at the international workshop on "Which accounting regulation for Europe's economy and society?" organised under the auspices of the European Parliament in Strasbourg, on 20 May 2015, in tribute to Mr Jérôme Haas (1963-2014), first chairman of the Accounting Standards Authority of France (ANC). It was organised by the Laboratory of Excellence on Financial Regulation (Labex ReFi), which is supported by PRES heSam under the reference ANR-10-LABX-0095. It benefits by a French government grant by the National Research Agency (ANR) under the funding program Investissements d'Avenir Paris Nouveaux Mondes (Investments for the future Paris - New Worlds) reference ANR-11-IDEX-0006-02.

\section{References}

Bensadon, D., \& Praquin, N. (Eds.). (2016). IFRS in a global world. Essays in honour of professor Jacques Richard. Heidelberg, New York, \& Dordrecht: Springer.

Biondi, Y. (2011). The pure logic of accounting: A critique of the fair value revolution.

Accounting, Economics and Law, 1, 2-46.

Busse von Colbe, W. (1996). Accounting and the business economics tradition in Germany. European Accounting Review, 5, 413-434.

Canziani, A. (1988). International Group Accounting. In S. J. Gray \& A. G. Coenenberg (Eds.), Italy and the seventh directive (pp. 105-116). Londra, New York, \& Sidney: Croom Helm 
Canziani, A. (2013). Routledge Companion on Accounting and Business Economics. In Y. Biondi \& S. Zambon (Eds.), Accounting and Economia Aziendale in Italy, 1911 afterwards (pp. 69101). London: Routledge.

Canziani, A. (2016). IFRS in a global World. Essays in Honour of Professor Jacques Richard. In D. Bensadon \& N. Praquin (Eds.), The transition to IFRS in Italy and elsewhere, or from Code Napoléon to the devolution of sovereignity (pp. 295-310). Heidelberg - New York Dordrecht: Springer.

Cohen, J. L. (2012). Gobalization and sovereignty. Rethinking legality, legitimacy, and constitutionalism. Cambridge, New York, \& Melbourne: Cambridge U.P.

Flint, D. (1982). A true and fair view in company accounts. London: Gee \& Co.

Gray, S. (1988). Towards a theory of cultural influence on the development of accounting systems internationally. Abacus, 1, 1-15.

Gray, S. J., \& Coenenberg, A. G. (Eds.). (1988). International group accounting. Londra, New York, \& Sidney: Croom Helm.

Rayman, A. (2006). Accounting standards: True or false? London: Routledge.

Richard, J. (2005, August). The concept of fair value in French and German accounting regulations from 1673 to 1914 and its consequences for the interpretation of the stages of development of capitalistic accounting. Critical Perspectives in Accounting, 16, 825-850. 